\title{
Decolorization of Methylene Blue Dye Using Sonocatalytic Followed by Photocatalytic Process
}

\author{
Ramanathan Balakumara $^{1} \cdot$ Karunakaran Sathya $^{1} \cdot$ Ramanujam Saravanathamizhan $^{1}$
}

Received: 9 May 2016 /Revised: 23 June 2016 / Accepted: 25 July 2016 / Published online: 5 August 2016

(C) Springer Science+Business Media Singapore 2016

\begin{abstract}
The aim of the present investigation is to study the different methods to improve the photocatalytic decolorization using visible light photocatalyst. In this investigation, $\mathrm{ZnO} /$ $\mathrm{Bi}_{2} \mathrm{O}_{3}$ composite was prepared using hydrothermal method, and it is studied for the decolorization of methylene blue (MB) dye. Enhancement of decolorization has been done by ultrasonication followed by photocatalytic process. Considerable improvement was observed in sonocatalysis followed by photocatalytic process. Various operating parameters have been studied and optimized for the maximum decolorization of dye wastewater. It is observed from the present result that the sonocatalysis followed by photocatalysis is found to be the more efficient method for the treatment of wastewater.
\end{abstract}

Keywords Decolorization · Hydrothermal method .

Methylene blue dye $\cdot$ Photocatalysis $\cdot$ Sonocatalysis $\cdot \mathrm{ZnO} /$

$\mathrm{Bi}_{2} \mathrm{O}_{3}$ catalyst

\section{Introduction}

Wastewater generated from the textile industry causes color and odor and it contains high amount of COD and BOD. The large volume of wastewater released to the environment not only causes adverse effect to human health but also reduces the freshwater resources. Hence, it is not only important to treat the effluent but also to conserve freshwater. Water

Ramanujam Saravanathamizhan

thamizhan79@rediffmail.com

1 Department of Chemical Engineering, A. C. Tech, Anna University, Chennai 600025, India conservation and water loss reduction is always an integral part of the management of freshwater. Generally, the traditional tertiary process is used to remove color and odor and to clean the wastewater. But the major disadvantage in this method is that it releases toxic carcinogenic products. Hence, to overcome the disadvantage, several oxidation methods such as Fenton process [1], ozonation, sonication [2-5], and photocatalytic process [6-8] are introduced.

Fenton process produces iron sludge during the treatment process, and separation of iron through precipitation is a tedious process. It also needs limited $\mathrm{pH}$ range of about 2 to 3 [9]. Ozonation treatment process has the disadvantage of limited half-life period. In the sonication process, sound released creates excess pressure and temperature among the bubbles that break the bonds of the molecules. But the removal efficiency is very low, since it cannot degrade the higher pollutant volume. Hence, photocatalytic treatment has been selected to treat the effluent since only light irradiation is used and no chemicals will involve in this process which is a major advantage. But photocatalytic process as an individual process is rather slow. Therefore, to enhance the degradation efficiency, many hybrid advanced oxidation processes (AOPs) such as electro-Fenton, $\mathrm{UV} / \mathrm{H}_{2} \mathrm{O}_{2}, \mathrm{O}_{3} /$ $\mathrm{H}_{2} \mathrm{O}_{2}$ photo-Fenton, and sonophotocatalytic process are used to degrade the effluent $[10,11]$. Various ferrites, oxyhalides, semiconductor oxides, and vanadates such as $\mathrm{WO}_{3}, \mathrm{BiVO}_{4}, \mathrm{Cu}_{2} \mathrm{O}$, $\mathrm{ZnO}, \mathrm{CeO}_{2}, \mathrm{BiOBr}$, and $\mathrm{GO}$ are used as a photocatalyst [12-15]. In order to enhance the photocatalyst, various methods such as doping and composites of various catalysts are reported in the literature [16]. Sharm and Lee [17] investigated nickel-doped titanium nanocomposite as an adsorbent and a photocatalyst for naphthalene removal from aqueous phase. The author reported that 2.5 times higher removal was achieved by the nanocomposite in the presence of visible light compared to $\mathrm{TiO}_{2}$ alone. The same authors [18] also investigated and synthesized cobalt oxide-loaded $\mathrm{TiO}_{2}$ further supported with reduced graphene 
oxide for the degradation of 2-chlorophenol under visible light irradiation. The authors observed that the incorporation of cobalt oxide-loaded $\mathrm{TiO}_{2}$ supported with reduced graphene oxide might improve the photocataytic activity and reported $98.2 \%$ degradation efficiency.

The $\mathrm{Bi}_{2} \mathrm{O}_{3}$ catalyst can be excited by visible light with a band gap of $2.8 \mathrm{eV}$ and it has been proven to be an efficient photocatalyst [14]. But $\mathrm{Bi}_{2} \mathrm{O}_{3}$ alone shows lower photocatalytic activity, due to its higher recombination rate. The catalyst having higher recombination rate will have lower photocatalytic efficiency [19]. For this, heterojunction may be done. Heterojunction is combination of two dissimilar semiconductors of different energy band gaps in order to slow down the recombination rate. Hence, heterojunction or coupling of semiconductors had been selected in order to restrain the recombination. Here, $\mathrm{ZnO}$ is taken for coupling since it has higher potential in photocatalytic activity of wide energy band gap $(3.2 \mathrm{eV})$. In this experiment, the p-n type semiconductor of $\mathrm{ZnO} / \mathrm{Bi}_{2} \mathrm{O}_{3}$ is used. The objective of the present work is to prepare the $\mathrm{ZnO} / \mathrm{Bi}_{2} \mathrm{O}_{3}$ catalyst using hydrothermal method and study the sonocatalytic followed by photocatalytic decolorization of synthetic dye wastewater.

\section{Materials and Methods}

\section{Synthesis of Zinc Oxide-Bismuth Oxide Catalyst Using Hydrothermal Method}

Commercial $\mathrm{ZnO}$ and $\mathrm{Bi}_{2} \mathrm{O}_{3}$ powders were purchased from Sigma Aldrich and used without any further purification. The composites were prepared according to Maryam et al., [20] where the commercial zinc oxide of about $0.5 \mathrm{~g}$ was dissolved in $0.2 \mathrm{~mol}$ of $\mathrm{NaOH}$. On continuous stirring, about $0.5 \mathrm{~g}$ of commercial bismuth oxide was added. The mixture was taken in Teflon-lined stainless steel autoclave and kept in temperature of $80^{\circ} \mathrm{C}$ for $24 \mathrm{~h}$. The solution was then decanted and washed by distilled water and ethanol for five times and the resulting precipitate was dried in the hot air oven for $12 \mathrm{~h}$ at $60{ }^{\circ} \mathrm{C}$.

\section{Experimental}

The experiment for the present investigation is carried out in an ultrasonicator followed by photochamber. Synthetically, prepared methylene blue (MB) dye is taken in the sonicator. Sonicator consists of cylindrical jacketed stainless steel reactor equipped with inbuilt piezoelectric transducer placed at the rectangular bottom and an external generator is used. The bath type can deliver fixed frequency of $36 \mathrm{kHz}$. The setup is connected to AC power supply. After sonication, the solution is subjected to photocatalytic process. The photocatalytic apparatus consists of three $300 \mathrm{~W}$ xenon lamps consisting of magnetic stirrer to maintain the uniform mixing of the solution. It has UV filter cap so that it will not allow light of range below $420 \mathrm{~nm}$. Cooling fans are provided in the chamber to control the temperature. Experiments were conducted for sonocatalytic followed by photocatalytic process. After a definite time interval, the samples were collected from the conical flask and were analyzed for color removal.

\section{Result and Discussion}

\section{XRD (X-Ray Diffraction) Measurement}

An XRD pattern of $\mathrm{ZnO} / \mathrm{Bi}_{2} \mathrm{O}_{3}$ composite is shown in Fig. 1 . The peaks were formed according to Maryam et al. [20]. The
Fig. 1 XRD result of the catalyst used for the sonocatalysis followed by photocatalysis process at angle 2 theta

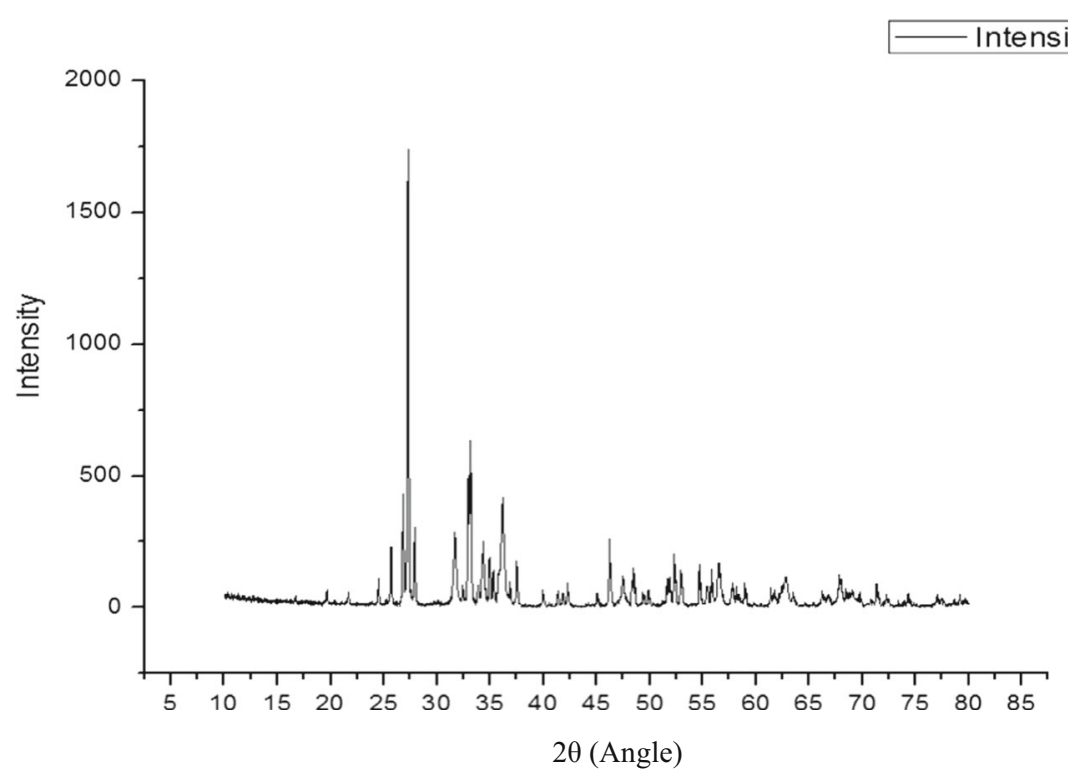


peaks formed at $27.2^{\circ}$ and $33.7^{\circ}$ confirm the presence of $\mathrm{Bi}_{2} \mathrm{O}_{3}$ (JCPDS No. 71-2274). The peaks formed at $31.69^{\circ}, 34.9^{\circ}$, and $36.1^{\circ}$ indicate the presence of zinc oxide ( $\mathrm{ZnO}$ ) (JCPDS No . 79-2205). The other peaks formed in the analysis show the crystalline nature of the sample. Thus, from the XRD analysis, it shows that the $\mathrm{ZnO} / \mathrm{Bi}_{2} \mathrm{O}_{3}$ composite had been formed.

\section{Band Gap Energy of Photocatalyst}

UV DRS of the $\mathrm{ZnO} / \mathrm{Bi}_{2} \mathrm{O}_{3}$ catalyst is shown in Fig. 2. It is noticed from the figure that the maximum wavelength was observed at $463 \mathrm{~nm}$. The band gap has been calculated using the formula ( $\mathrm{E}=1240 / \lambda$ where $\lambda$ is the wave length) and found to be $2.67 \mathrm{eV}$. It is evident that $\mathrm{ZnO}(3.2 \mathrm{eV})$ and $\mathrm{Bi}_{2} \mathrm{O}_{3}(2.8 \mathrm{eV})$ form a composite $\left(\mathrm{ZnO} / \mathrm{Bi}_{2} \mathrm{O}_{3}\right)$ having the band gap energy of $2.67 \mathrm{eV}$ which can be used effectively as a visible light photocatalyst.

\section{Decolorization of Methylene Blue Dye on Individual and Sequential Process}

The effect of different processes such as sonolysis, photocatalysis, and sonication (catalyst is not added during sonication) followed by photocatalysis and sonocatalysis (catalyst is added during sonication) followed by photocatalysis on color removal of methylene blue dye is shown in Fig. 3. For all processes, $10 \mathrm{mg} \mathrm{L}^{-1}$ of MB dye concentration was taken and $1 \mathrm{~g} \mathrm{~L}^{-1} \mathrm{ZnO} / \mathrm{Bi}_{2} \mathrm{O}_{3}$ catalyst has been added. In photocatalytic process, $93.97 \%$ of color removal was achieved at the end of $135 \mathrm{~min}$. The reason behind this is that due to heterojunction of two semiconductors, the electrons that get excited due to the light irradiation get transferred from $\mathrm{ZnO}$ to $\mathrm{Bi}_{2} \mathrm{O}_{3}$ due to the band gap energy of about $3.2 \mathrm{eV}$ and $2.8 \mathrm{eV}$, respectively. Also, the electron holes get transferred from $\mathrm{Bi}_{2} \mathrm{O}_{3}$ to $\mathrm{ZnO}$, due to this recombination rate gets reduced and $\mathrm{OH}$ radicals formed. In sono followed by

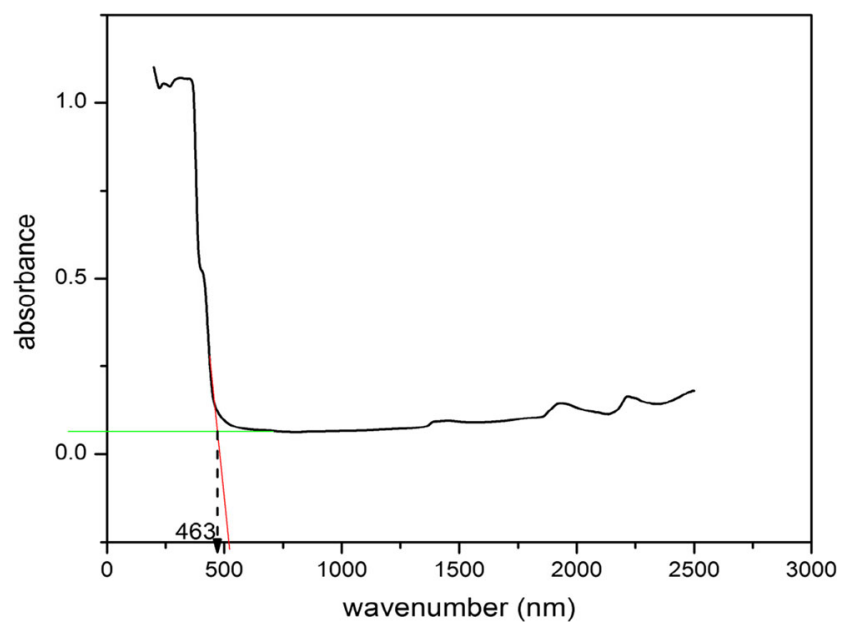

Fig. 2 UV DRS of the $\mathrm{ZnO} / \mathrm{Bi}_{2} \mathrm{O}_{3}$ catalyst

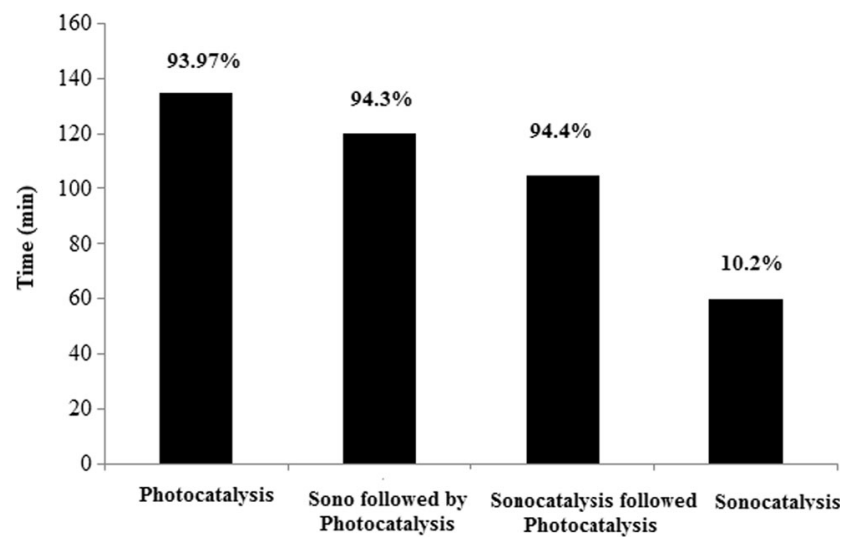

Fig. 3 Decolorization of MB dye individual and sequential process. Initial methylene blue dye concentration: $10 \mathrm{mg} \mathrm{L}^{-1}$, catalyst dosage: $1 \mathrm{~g} \mathrm{~L}^{-1}$, light intensity: $300 \mathrm{~lx}$

photocatalytic process about $94.3 \%$ of color removal was achieved at the end of $120 \mathrm{~min}$. The reason behind is that due to sonication $\mathrm{OH}^{*}$, radicals formed will be higher and hence the color removal occurs in faster rate than that of individual process. In sonocatalysis followed by photocatalysis process, about $94.4 \%$ of color removal was observed within $105 \mathrm{~min}$. This is due to the reason disaggregation of catalyst by ultrasonic vibrations, thus increasing surface area of catalyst [21]. In sonocatalysis method, only $10.2 \%$ removal was observed. There is no further color removal that was observed in the process. It is evident from all processes that efficient color removal at lesser time was achieved by sonocatalysis followed by photocatalysis.

\section{Effect of Light Intensity}

The effect of light intensity on percentage color removal has been studied for an initial dye concentration of $10 \mathrm{mg} \mathrm{L}^{-1}$ with $1 \mathrm{~g} \mathrm{~L}^{-1}$ of catalyst. The dye solution was sonicated and then kept in photocatalytic chamber. The light intensity has been varied and the result is shown in Fig. 4. It is observed from the figure that percentage color removal increases with increase in light intensity. This is due to that at the low light intensity, the light travelled to reach the catalyst will be low which results in less hydroxyl radical formation.

\section{Effect of Catalyst Dosage}

The effect of catalyst dosage on percentage color removal is shown in Fig. 5. It is observed from the figure that as the amount of catalyst increases, the time to achieve the color removal gets decreased. This is due to increase in surface area as catalyst dosage increases. 


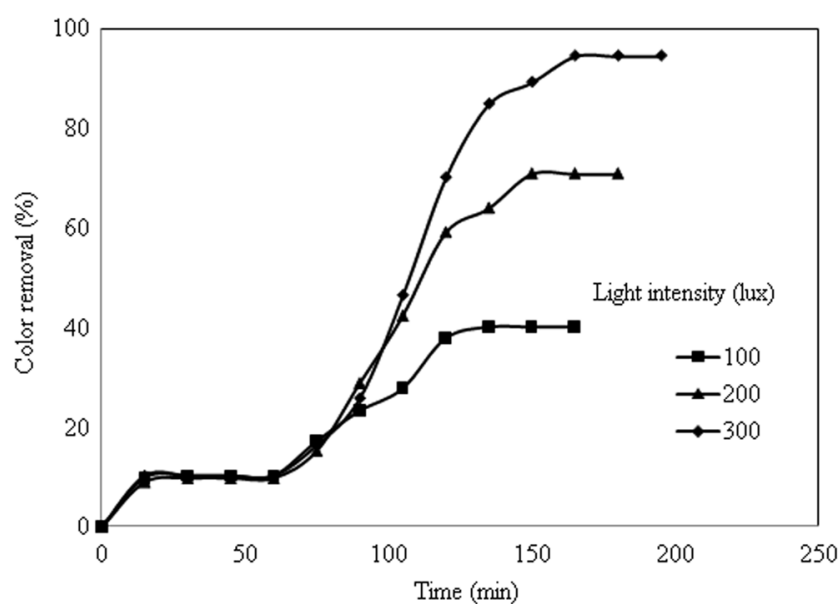

Fig. 4 Effect of light intensity on percentage color removal of MB dye. Initial methylene blue dye concentration: $10 \mathrm{mg} \mathrm{L}^{-1}$, catalyst dosage: $1 \mathrm{~g} \mathrm{~L}^{-1}$

\section{Effect of Initial Dye Concentration}

The effect of initial dye concentration on percentage color removal is shown in Fig. 6. It is observed from the figure that by increasing dye concentration, the percentage color removal gets decreased and the time taken for color removal of methylene blue increased. It is further noticed from Fig. 6, for $20 \mathrm{mg} \mathrm{L}^{-1}, 40 \mathrm{mg} \mathrm{L}^{-1}$, and $60 \mathrm{mg} \mathrm{L}^{-1}$ dye, the color removal was constant beyond $330 \mathrm{~min}$ and for the $80 \mathrm{mg} \mathrm{L}^{-1}$ dye, the color removal was constant after $420 \mathrm{~min}$. This is due to the reason that the higher concentration of dye solution absorbs the visible light and only certain amount of light is used for photo catalytic process thus decreasing formation of $\mathrm{OH}^{\bullet} \mathrm{rad}-$ ical. Hence, the percentage color removal is more for less dye concentration.

\section{Effect of pH}

The effect of $\mathrm{pH}$ on percentage color removal is shown in Fig. 7. It is observed that at neutral $\mathrm{pH}$, the color removal

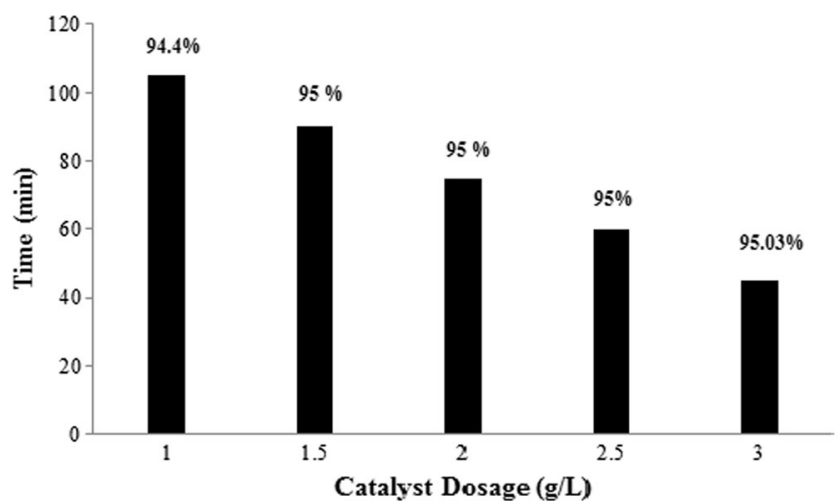

Fig. 5 Effect of catalyst dosage on percentage color removal of MB dye. Initial MB dye concentration: $10 \mathrm{mg} \mathrm{L}^{-1}$, light intensity: $300 \mathrm{~lx}$

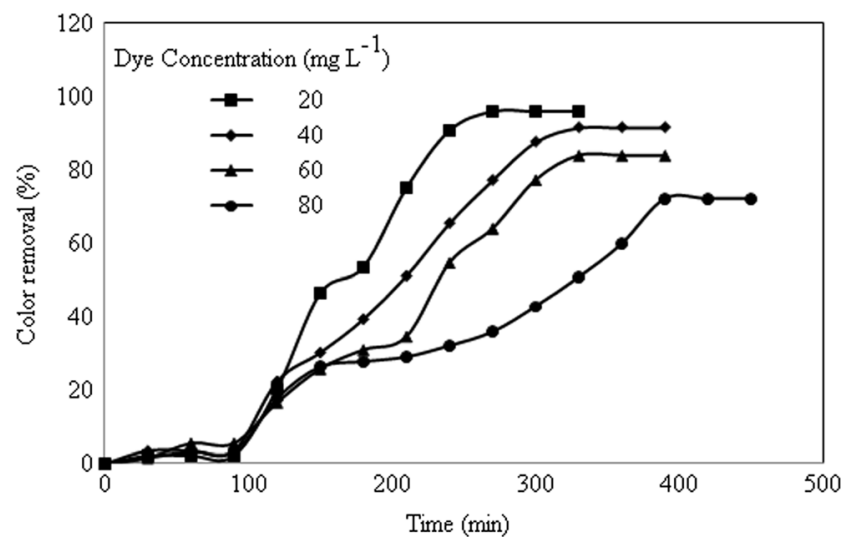

Fig. 6 Effect of initial dye concentration on percentage color removal of MB dye. Catalyst dosage: $1 \mathrm{~g} \mathrm{~L}^{-1}$, light intensity: $300 \mathrm{~lx}$

was $97 \%$, and at $\mathrm{pH} 4$, the color removal was $63 \%$. Also, the color removal gets decreased from 97 to $89 \%$ at $\mathrm{pH} 11$. At acidic conditions, $\mathrm{ZnO}$ gets dissoluted [22], and hence the color removal will be very low. The higher efficiency at neutral $\mathrm{pH}$ may be due to the reason that surface charge density of the catalyst may have been changed from positive to negative [23]. Since methylene blue is cationic and charge density of the catalyst is negative, it leads to electrostatic attraction and thus increasing the removal efficiency. At alkaline $\mathrm{pH}$, it again decreases because hydroxyl groups formed will be more leading to scavenging effect, in which initially color removal is higher, but later on, the color removal decreases with increasing time due to decomposition of the catalyst.

\section{Reusability of the Catalyst}

To test the reusability, the already used catalyst was washed with ethanol and kept in air oven. The dried catalyst was then taken and used in the photocatalytic pro-

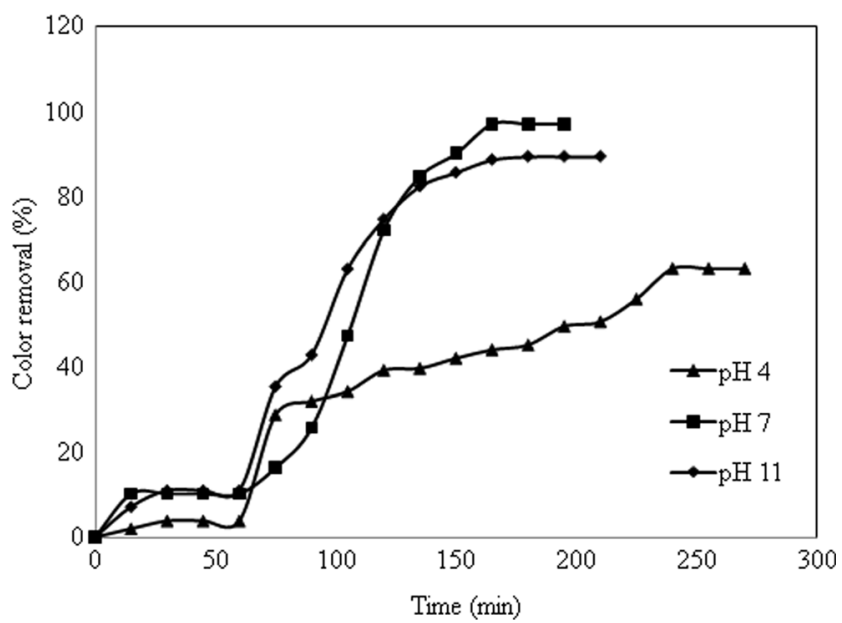

Fig. 7 Effect of $\mathrm{pH}$ on percentage color removal of $\mathrm{MB}$ dye. Initial MB dye concentration: $10 \mathrm{mg} \mathrm{L}^{-1}$, catalyst dosage: $1 \mathrm{~g} \mathrm{~L}^{-1}$, light intensity: $3001 \mathrm{x}$ 
cess. The effect of reusability of the catalyst is shown in Fig. 8. It is observed from the figure that the percentage color removal decreases $(91,87$, and $81 \%$, respectively) as the number of reusable cycle of catalyst increases.

\section{Kinetics of Photocatalytic Process}

Kinetic study of methylene blue color removal has been performed for different initial dye concentrations. The kinetics of the color removal can be written as follows:

$-\frac{d C}{d t}=k C$

The equation can be written as a pseudo first order reaction with respect to color removal:

$-\ln \left(\frac{C_{\mathrm{t}}}{C_{0}}\right)=k t$

Where $C_{0}$ is the initial absorbance of the dye, $C_{\mathrm{t}}$ is the absorbance of the dye as a function of time, $t$, and $k$ is the rate constant. The term $-\ln \left(C_{t} / C_{0}\right)$ was plotted versus time and the slope gives $k$ value of rate constant. The $k$ value for the percentage color removal in each experimental condition is calculated. The kinetics study of methylene blue for color removal for various initial concentrations is shown in Fig. 9. It is observed from the figure, $-\ln \left(C_{\mathrm{t}} / C_{0}\right)$ versus time " $t$ " follows the straight line. The correlation coefficients are regarded as an index of the goodness-of-fit to the first order kinetics. The $R^{2}$ values of dye decolorization of photo catalysis process are typically $\geq 0.920$. It can be observed from the figure that the color removal follows the first order kinetics having the rate constants of $0.015,0.008$, and $0.006 \mathrm{~min}^{-1}$ for 20,30 , and $40 \mathrm{mg} \mathrm{L}^{-1}$ of initial concentration of dye solution.

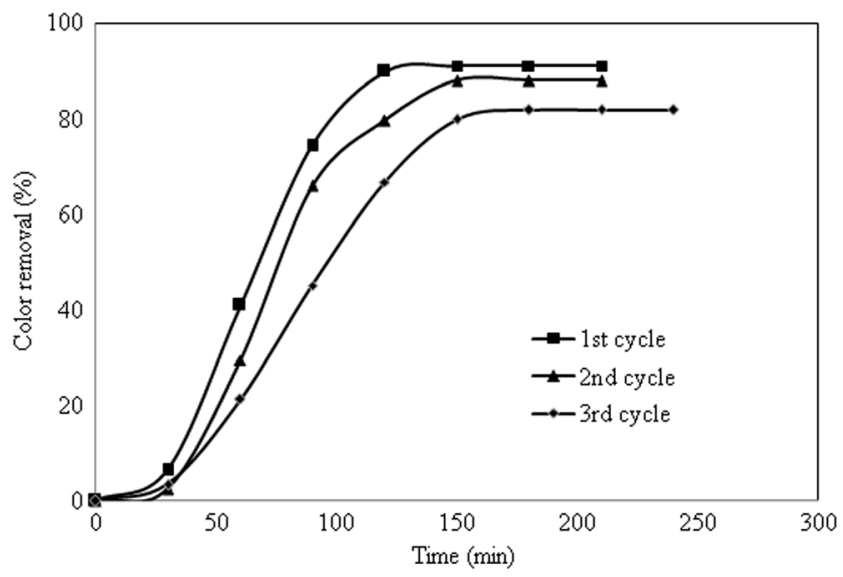

Fig. 8 Effect of catalyst reusability on percentage color removal of MB dye. Initial $\mathrm{MB}$ dye concentration: $10 \mathrm{mg} \mathrm{L}^{-1}$, catalyst dosage: $1 \mathrm{~g} \mathrm{~L}^{-1}$, light intensity: $300 \mathrm{~lx}$

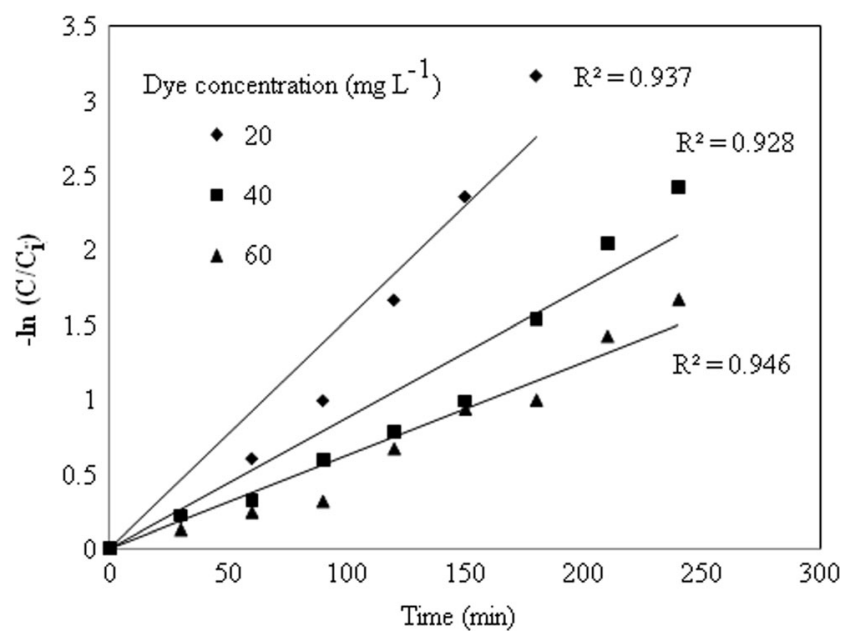

Fig. 9 Kinetics MB dye color removal using photo catalysis. Catalyst dosage: $1 \mathrm{~g} \mathrm{~L}^{-1}$, light intensity: $300 \mathrm{~lx}$

\section{Conclusion}

The $\mathrm{ZnO} / \mathrm{Bi}_{2} \mathrm{O}_{3}$ composite catalyst was prepared and its photocatalytic property was investigated. The effect of various combinations of processes such as sono followed by photocatalysis and sonocatalysis followed by photocatalysis were experimentally investigated. It has been observed that all the processes achieved good color removal efficiency while in combination of process; reaction gets faster than that of the individual process. The effect of catalyst dosage, initial dye concentration, $\mathrm{pH}$, and light intensity also has been experimentally investigated on color removal of the dye. The band gap of the photocatalyst had been found by UV-diffuse reflectance spectroscopy and found out to be $2.67 \mathrm{eV}$. The reusability of the catalyst was tested for three cycles; the percentage color removal was found out to be 91,87 , and $81 \%$, respectively.

\section{References}

1. Liang J, Komarov S, Hayashi N, Kasai E (2007) Recent trends in the decomposition of chlorinated aromatic hydrocarbons by ultrasonic irradiation and Fenton's reagent. J Mater Cycles Waste Manag 9:47-55

2. Tezcanli-Guyer G, Ince NH (2003) Degradation and toxicity reduction of textile dyestuff by ultrasound, journal of Ultrason. Sonochem 10:235-240

3. Lin X, Huang F, Wang W, Shan Z, Shi J (2008) Methyl orange degradation over a novel Bi-based photocatalyst $\mathrm{Bi}_{3} \mathrm{SbO}_{7}$ : correlation of crystal structure to photocatalytic activity. Journal of Dyes Pigments 78:39-47

4. Vajnhandl S, Le Marechal AM (2005) Ultrasound in textile dyeing and the decoloration/mineralization of textile dyes. Journal of Dye Pigments 65:89-101 
5. Wang L, Zhu L, Luo W, Wu Y, Tang H (2007) Drastically enhanced ultrasonic decolorization of methyl orange by adding $\mathrm{CCl}_{4}$. Journal of Ultrasonics Sonochemistry 14:253-258

6. Madhavan J, Muthuraaman B, Murugesan S, Anandan S, Maruthamuthu P (2006) Degradation of acid red 88 by the combination of sonolysis and photocatalysis. Journal of Solar Cell 90: 1875-1887

7. Saquib M, Muneer M (2007) Photocatalytic degradation of CI acid green 25 and CI acid red 88 in aqueous suspensions of titanium dioxide. Journal of Color Technology 118:307-315

8. SathishKumar P, Sivakumar R, Anandan S, Madhavan J, Maruthamuthu P, Ashokkumar M (2008) Photocatalytic degradation of acid red 88 using $\mathrm{Au}-\mathrm{TiO}_{2}$ nanoparticles in aqueous solutions. J Water Res 42:4878-4884

9. Babuponnusami A, Muthukumar K (2014) A review on Fenton and improvements to the Fenton process for wastewater treatment. Journal of Environmental Chemical Engineering 2:557-572

10. Neppolian B, Choi HC, Sakthivel S, Arabindoo B, Murugesan V (2002) Solar/UV-induced photocatalytic degradation of three commercial textile dyes, journal of hazard. Materials 89:303-317

11. Hoffmann MR, Martin ST, Choi W (1995) Environmental applications of semiconductor photocatalysis. Journal of Chemistry 95:6996

12. He Z, Lin L, Song S, Xia M, Xu L, Ying H, Chen J (2008) Mineralization of CI reactive blue 19 by ozonation combined with sonolysis: performance optimization and degradation mechanism, journal of separation and. Purification Technology 62:376-381

13. Kim SH, Shon HK, Vigneswaran S (2008) Adsorption and photocatalysis kinetics of herbicide onto titanium oxide and powdered activated carbon, journal of separation and. Purification Technology 58:335-342
14. Agatino DP, Elisa GL, Giuseppe M, Leonardo P (2012) A survey of photocatalytic materials for environmental remediation. J Hazard Mater 29:211-212

15. Arumugam $\mathrm{M}$, Sha $\mathrm{HH}$ (2010) Synthesis of mesoporous $\mathrm{Bi}_{2} \mathrm{O}_{3} /$ $\mathrm{CeO}_{2}$ microsphere for photocatalytic degradation of orange II dye. Journal of Research material 48:4174 4180

16. Vadivel K, Balasubramanian N (2014) Graphene oxide-BiOBr composite material as highly efficient photocatalyst for degradation of methylene blue and rhodamine blue. Journal of water process Engineering 1:17-26

17. Sharma A, Lee B-K (2015) Adsorptive/photo-catalytic process for naphthalene removal from aqueous media using in-situ nickel doped titanium nanocomposite. J Environ Manag 155:114-122

18. Sharma A, Lee B-K (2016) Rapid photo-degradation of 2chlorophenol under visible light irradiation using cobalt oxideloaded $\mathrm{TiO}_{2} /$ reduced graphene oxide nanocomposite from aqueous media. J Environ Manag 165:1-10

19. Song L, Zhang S (2010) Preparation and visible light photocatalytic activity of $\mathrm{Bi}_{2} \mathrm{O}_{3} / \mathrm{CaO}$ photocatalysts. Reac Kinet Mech Cat 99: 235-241

20. Maryam M, Akram H, Nasrin N, Mohadeseh R, Hossein S (2015) Synthesis of $\mathrm{ZnO} / \mathrm{Bi}_{2} \mathrm{O}_{3}$ and $\mathrm{SnO}_{2} / \mathrm{Bi}_{2} \mathrm{O}_{3} / \mathrm{Bi}_{2} \mathrm{O}_{4}$ mixed oxides and their photocatalytic activity. Journal of Chemistry 3:374-387

21. Kavitha SK, Palanisamy PN (2011) Photocatalytic and Sonophotocatalytic degradation of reactive red 120 using dye sensitized $\mathrm{TiO}_{2}$ under visible light. Journal of Chemistry 40:85-89

22. Khodja AA, Sehli T, Boule P (2011) Photocatalytic degradation of 2-phenyl phenolon $\mathrm{TiO}_{2}$ and $\mathrm{ZnO}$ on aqueous suspensions. Journal of Photochemistry and photobiology 141:231-239

23. Alkaim AF, Aljeboree AM, Alrazaaq NL (2014) Effect of pH on adsorption and photocatalytic degradation efficiency of different catalysts on removal of methylene blue. Asian J Chem 24:8445-8448 